06.5

\title{
Исследование влияния облучения ускоренными электронами на физические свойства полиэтилентерефталата
}

\author{
(C) В.А. Шарапова ${ }^{1}$, И.С. Каманцев ${ }^{2}$, В.П. Швейкин ${ }^{2}$, В.Ю. Иванов ${ }^{1}$, О.В. Рябухин ${ }^{1}$ \\ ${ }^{1}$ Уральский федеральный университет им. Б.Н. Ельцина, Екатеринбург, Россия \\ ${ }^{2}$ Институт машиноведения УрО РАН, Екатеринбург, Россия \\ E-mail: v.a.sharapova@urfu.ru
}

Поступило в Редакцию 29 октября 2021 г.

В окончательной редакции 2 декабря 2021 г.

Принято к публикации 6 декабря 2021 г.

\begin{abstract}
Проведено исследование влияния облучения ускоренными электронами (энергия $8.5 \mathrm{MeV}$, доза $5 \mathrm{kGy}$ ) на физические свойства медицинских изделий из полиэтилентерефталата методами инфракрасной спектроскопии. Выявленные пострадиационные изменения спектров могут быть использованы при обосновании выбора дозы облучения изделий из полиэтилентерефталата электронами при процедуре радиационной стерилизации.
\end{abstract}

Ключевые слова: полиэтилентерефталат, облучение ускоренными электронами.

DOI: 10.21883/PJTF.2022.05.52153.19068

Внедрение радиационных технологий в производство или постобработку изделий из полимеров и пластиков обусловливает актуальность исследования процессов, происходящих в таких материалах под воздействием излучения [1]. Наиболее широко потребляемым в сегменте полиэфирных волокон является полиэтилентерефталат (ПЭТФ). ПЭТФ-тара в настоящее время активно вытесняет такие традиционные виды аптечной, медицинской и лабораторной тары, как стекло и картон. Однако вследствие своей термочувствительности медицинские изделия из ПЭТФ требуют так называемых „холодных“ методов стерилизации. Сегодня существуют методы щадящей „холодной“ стерилизации медицинских изделий низкотемпературной атмосферной плазмой [2], позволяющей достичь необходимого бактерицидного эффекта с сохранением требуемых физико-химических свойств медицинских изделий. При этом промышленной методикой стерилизации медицинских изделий, позволяющей стерилизовать объекты непосредственно в герметичной упаковке, является обработка ускоренными электронами с энергиями ниже порога возникновения ядерных реакций (обычно до $10 \mathrm{MeV}$ ). Метод позволяет в короткие сроки обрабатывать большие объемы продукции без вскрытия заводской упаковки. ГОСТ ISO 11137-1-2011, регламентирующий процедуру радиационной стерилизации в Российской Федерации, определяет диапазон стерилизационной дозы в $15-25 \mathrm{kGy}$. Выбор дозы из нормируемого диапазона прежде всего выполняется исходя из условий обеспечения установленных требований к стерильности. С другой стороны, процедура радиационной стерилизации не должна существенно ухудшать потребительские свойства изделий [3]. В связи с этим актуальным представляется поиск чувствительных методов оценки пострадиационного изменения физикохимических свойств медицинских изделий из ПЭТФ.
Материалом для исследования служили образцы медицинских пробирок из ПЭТФ для забора крови производства АО „Здравмедтех-Е“. Оценка изменения их свойств осуществлялась методами ИК-спектроскопии [4]. Облучение образцов выполнялось ускоренными электронами в Инновационно-внедренческом центре радиационной стерилизации Уральского федерального университета. Величина дозы облучения составляла $5 \mathrm{kGy}$ при энергии электронов $8.5 \mathrm{MeV}$ (табл. 1). При этом в настоящей работе не ставилась задача установления нижнего порога стерилизационной дозы, а основной целью работы была оценка чувствительности метода ИК-спектроскопии к определению начальных стадий изменения физико-химических свойств облучаемых материалов.

Известно [5], что воздействие ионизирующего излучения приводит к изменению физико-химических свойств материалов. Также, согласно исследованию [6], для данного материала доза облучения электронами в $1 \mathrm{MGy}$ приводит к падению предела прочности на 15-30\%. В связи с тем, что от химического состава и строения веществ зависят также их колебательные и оптические спектры, было принято решение проанализировать изменение пропускания через пробирки ИК-излучения [7].

Регистрация ИК-спектров проводилась в лаборатории „Комплексных исследований и экспертной оценки органических материалов“ Центра коллективного пользования Уральского федерального университета на инфракрасном фурье-спектрометре Bruker Alpha в диапазоне частот от 4000 до $500 \mathrm{~cm}^{-1}$ (разрешение $1 \mathrm{~cm}^{-1}$ ) с использованием приставки однократного горизонтального наружного полного внутреннего отражения (Eco-ART) с кристаллом ZnSe (область прозрачности 0.5-20 $\mathrm{m}$, показатель преломления $n=2.42$ ). Математическая обработка результатов была выполнена с помощью программного обеспечения Fityk [8]. 
Таблица 1. Сведения о пробирках, использованных для изготовления образцов

\begin{tabular}{|c|c|c|c|}
\hline Индекс пробирки & Марка заводская & Объем, $\mathrm{ml}$ & Доза облучения, kGy \\
\hline $\begin{array}{l}\mathrm{I}_{0} \\
\mathrm{I}_{5}\end{array}$ & К2ЭДТА & 5 & $\begin{array}{l}0 \\
5\end{array}$ \\
\hline $\begin{array}{l}\mathrm{II}_{0} \\
\mathrm{II}_{5}\end{array}$ & Кремнезем & 9 & $\begin{array}{l}0 \\
5\end{array}$ \\
\hline $\begin{array}{l}\mathrm{III}_{0} \\
\mathrm{III}_{5}\end{array}$ & КЗЭДТА & 2 & $\begin{array}{l}0 \\
5\end{array}$ \\
\hline
\end{tabular}
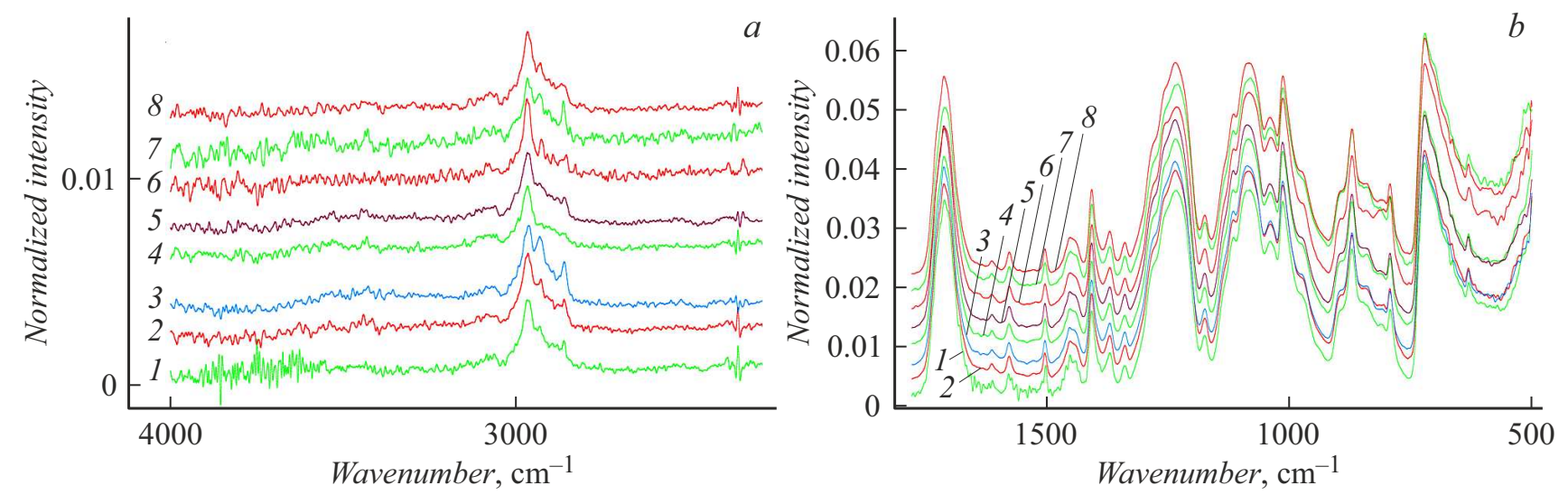

Рис. 1. ИК-спектры исходных пробирок $\left(1-\mathrm{I}_{0} ; 3,4-\mathrm{II}_{0} ; 7-\mathrm{III}_{0}\right)$ и пробирок после облучения $\left(2-\mathrm{I}_{5} ; 5,6-\mathrm{II}_{5} ; 8-\mathrm{III}_{5}\right)$. Спектры $1,4,7$ и 2, 6, 8 получены с целых пробирок, спектры 3 и $5-$ с пластинок, вырезанных из пробирок марки „Кремнезем“ (табл. 1). $a$ - область спектра $4000-1800 \mathrm{~cm}^{-1}, b-1800-500 \mathrm{~cm}^{-1}$.

ИК-спектроскопия позволяет получить информацию о наличии определенных функциональных групп, их количестве, строении молекул, составляющих вещество, видах связи между молекулами. В рамках задачи настоящей работы ИК-спектры позволяют определить факт влияния радиационного воздействия на структуру и состав ПЭТФ. На рис. 1 представлены спектры после нормирования по величине интегральной интенсивности полосы $1410 \mathrm{~cm}^{-1}$ — „внутренний стандарт“ [9]. Нормирование заключалось в следующем: 1) вычитание наклонного линейного фона по минимумам поглощения в окрестностях полосы $1410 \mathrm{~cm}^{-1}$; 2) измерение площади под пиком поглощения $1410 \mathrm{~cm}^{-1}$; 3) вычисление отношений максимального значения площади к остальным; 4) умножение каждого ИК-спектра на величину, полученного отношения для данного спектра.

В табл. 2 показаны величины относительных интенсивностей полос: валентных колебаний карбонильной группы $\mathrm{C}=\mathrm{O}-1712 \mathrm{~cm}^{-1}$; эфирной группы $1234 \mathrm{~cm}^{-1}$; совокупности метиленовых групп и связей $\mathrm{C}-\mathrm{O}$ эфирной группы $-1084 \mathrm{~cm}^{-1}$; взаимодействия полярных групп с бензольным кольцом $-720 \mathrm{~cm}^{-1}$ [10]. Первоначально спектры были получены с боковой поверхности целых пробирок (спектры 1,2,4,6-8), затем измерения повторились на двух полосах длиной $40 \mathrm{~mm}$,
Таблица 2. Относительные интенсивности полос 1712, 1234, $1084,720 \mathrm{~cm}^{-1}$

\begin{tabular}{c|c|c|c|c|c}
\hline \multirow{2}{*}{$\begin{array}{c}\text { Номер } \\
\text { спектра }\end{array}$} & \multirow{2}{*}{$\begin{array}{c}\text { Индекс } \\
\text { пробирки }\end{array}$} & \multicolumn{4}{|c}{ Волновое число, $\mathrm{cm}^{-1}$} \\
\cline { 3 - 6 } & 1712 & 1234 & 1084 & 720 \\
\hline 1 & $\mathrm{I}_{0}$ & 2.68 & 2.46 & 2.36 & 2.84 \\
2 & $\mathrm{I}_{5}$ & 2.65 & 2.48 & 2.38 & 2.73 \\
3 & $\mathrm{II}_{0}$ & 2.57 & 2.45 & 2.33 & 2.58 \\
4 & $\mathrm{II}_{0}$ & 2.60 & 2.52 & 2.43 & 2.82 \\
5 & $\mathrm{II}_{5}$ & 2.63 & 2.49 & 2.37 & 2.59 \\
6 & $\mathrm{II}_{5}$ & 2.51 & 2.44 & 2.53 & 2.97 \\
7 & $\mathrm{II}_{0}$ & 2.47 & 2.41 & 2.35 & 3.00 \\
8 & $\mathrm{III}_{5}$ & 2.73 & 2.55 & 2.44 & 2.84 \\
Средние значения & 2.60 & 2.48 & 2.40 & 2.80 \\
Дисперсии & 0.007 & 0.002 & 0.004 & 0.024 \\
Средние значения для & 2.58 & 2.46 & 2.37 & 2.81 \\
необлученных пробирок & & & & \\
Средние значения для & 2.63 & 2.49 & 2.43 & 2.78 \\
облученных пробирок & & & &
\end{tabular}

шириной $7 \mathrm{~mm}$ (спектры 3,5), вырезанных из пробирок марки „Кремнезем“ (табл. 1).

Из табл. 2 видно, что величины относительных интенсивностей не зависят от радиационного воздействия на образцы, хотя можно отметить незначительное уве- 


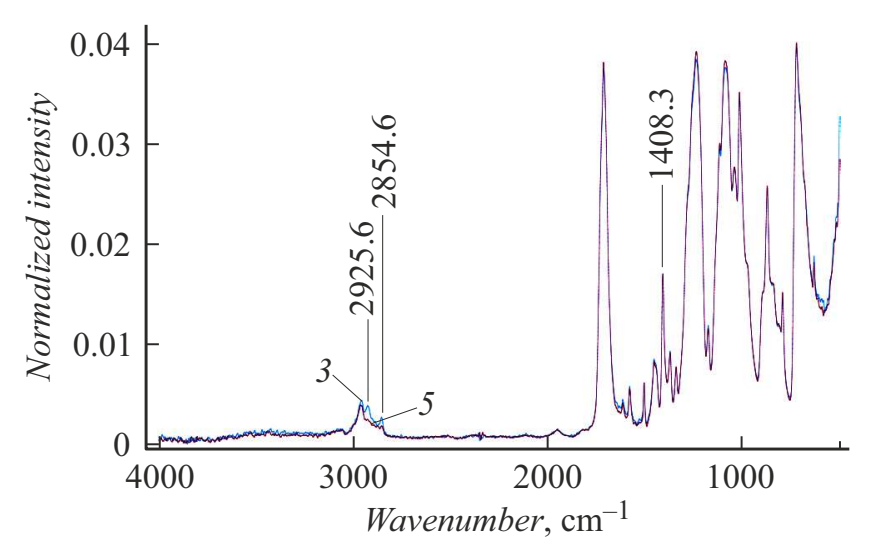

Рис. 2. ИК-спектры 3 и 5 . Нумерация спектров соответствует представленной на рис. 1.

личение параметров, приведенных в столбцах для 1712 , $1234,1084 \mathrm{~cm}^{-1}$, после облучения (строки со средними значениями). Однако из спектров 3 и 5 (представлены отдельно на рис. 2) следует, что область валентных колебаний связей $\mathrm{C}-\mathrm{H}_{2}$ изменяется после облучения. Последнее свидетельствует об уменьшении количества связей $\mathrm{C}-\mathrm{H}_{2}$, проявляющихся при волновых числах 2854.6 и $2925.6 \mathrm{~cm}^{-1}$.

Также на рис. 2 можно наблюдать пострадиационное увеличение интенсивности полос поглощения 1712 , $1234,1084,720 \mathrm{~cm}^{-1}$. Выше указывалось, что обработка спектров включала нормировку на интегральную интенсивность пика поглощения $1410 \mathrm{~cm}^{-1}$. Если верно предположение о деструктивном влиянии облучения на материал пробирок (см. отмеченное выше уменьшение интенсивности поглощения связей $\mathrm{C}-\mathrm{H}_{2}$ ), то объяснить рост поглощения указанных полос можно уменьшением площади внутреннего стандарта. Дополнительно была предпринята попытка нормировки спектров на интегральную интенсивность всего спектра в диапазоне $4000-500 \mathrm{~cm}^{-1}$. Однако результат оказался схожим с полученным в том случае, когда для нормирования использовался пик поглощения $1410 \mathrm{~cm}^{-1}$.

Результаты настоящей работы свидетельствуют о том, что воздействие ускоренными электронами (энергия $8.5 \mathrm{MeV}$, доза $5 \mathrm{kGy}$ ) на образцы из ПЭТФ вызывает изменения их ИК-спектров, обусловленные уменьшением числа связей $\mathrm{C}-\mathrm{H}$ вследствие процесса дегидрирования материала. Таким образом, анализ ИК-спектров ПЭТФ может быть использован для экспресс-оценки пострадиационной деградации параметров медицинских изделий и подбора оптимальной стерилизационной дозы.

\section{Конфликт интересов}

Авторы заявляют, что у них нет конфликта интересов.

\section{Список литературы}

[1] Controlling of degradation effects in radiation processing of polymers (International Atomic Energy Agency, Vienna, 2009), IAEA-TECDOC-1617.

[2] Е.К. Филиппова, Д.А. Карпов, А.В. Градобоев, В.Ф. Пичугин, Перспективные материалы, № 5, 5 (2016).

[3] И.И. Корнев, Стерилизация изделий медищинского назначения в лечебно-профилактических учреждениях (АНМИ, М., 2000).

[4] Контроль неразрушающий. Методы оптические: термины и определения, ГОСТ Р 53696-2009 (М., 2010).

[5] В.М. Станкевич, Ю.М. Плескачевский, В.В. Смирнов, в сб.: 4-я Межсдунар. конф. „Взаимодействие излучений с твердым телом“, под ред. В.В. Углова (Изд. центр БГУ, Минск, 2001), с. 297-299.

[6] Э.Р. Клиншпонт, В.К.Милинчук, В.И. Тупиков, Атомная энергия, 76 (5), 422 (1994).

[7] S.G. Prasad, A. De, U. De, Int. J. Spectr., 2011, 810936 (2011). DOI: $10.1155 / 2011 / 810936$

[8] M. Wojdyr, J. Appl. Cryst., 43 (5), 1126 (2010). DOI: $10.1107 / \mathrm{S} 0021889810030499$

[9] И. Дехант, Р. Данц, В. Киммер, Р. Шмольке, Инбракрасная спектроскопия полимеров, пер. с нем. под ред. Э.Ф. Олейника (Химия, М., 1976).

[10] A.P. dos Santos Pereira, M.H. Prado da Silva, É. Pereira Lima Júnior, A. dos Santos Paula, F.J. Tommasini, Mater. Res., 20 (2), 411 (2017).

DOI: 10.1590/1980-5373-MR-2017-0734

\section{Финансирование работы}

Работа выполнена при поддержке IAEA (МАГАТЭ) по контракту CRP F23035. 